\title{
THYROID DISORDERS IN PATIENTS WITH TYPE 2 DIABETES MELLITUS
}

\author{
Ayhan Zengi' ${ }^{1}$ Serap Unal Tilki², Timur Kose ${ }^{3}$ \\ ${ }^{1}$ Department of Endocrinology and Metabolism, Isparta State Hospital, Turkey \\ ${ }^{2}$ Department of Internal Medicine, Isparta State Hospital, Turkey \\ ${ }^{3}$ Department of Statistic, Ege University Hospital, Turkey
}

Aim: Increased thyroid volume and thyroid dysfunction (TD) in diabetics have been reported (1-3). The aim of this study is to investigate the prevalence of thyroid disorders in patients with type 2 diabetes mellitus in formerly iodine deficient area.

Method: We included 131 (73 females, 58 males) diabetics without a history of previous thyroid disease and symptoms. The demographic, medical and clinical data, laboratory results (Fasting plasma glucose(FPG), HbA1c, lipid profile, thyroid stimulating hormone(TSH), free throxine(fT4), free triiodothyronine(FT3) were recorded. The result of thyroid function was classified as subclinical hyperthyroidism(Schyper) (tsh $\leq 0,5 \mathrm{mIU} / \mathrm{L}$, Ft4 and fT3:normal), euthyroidism (tsh:0,5-4, fT4 and fT3:normal), subclinical hypothyroidism(Schypo) (tsh: 4,1-9,9, fT4 and fT3:normal). All participants were evaluated by thyroid ultrasonography (US) and thyroid volume(TV) were calculated by standard formula ( volume $(\mathrm{mL})=$ depth $(\mathrm{cm}) \times$ width $(\mathrm{cm}) \times$ length $(\mathrm{cm}) \times \pi / 6)$.

Results: There is a significant difference between females and males with respect to age, smoking habit, body mass index (BMI). No significant differences were found between two groups with respect to diabetes duration, FPG, HbA1c, lipids levels and thyroid function (Table 1). Sc-hyper, euthyroidism and sc-hypo were detected in 15 (11,4\%), 107 (81,7\%), 9 (6,9\%) patients, respectively. Ultrasonographic findings except TV were similar in two groups. Although TV was higher in males than females, the diameter of dominant nodule was not different (Table 1). In all patients, the frequencies of normal US, multinodular goiter (MNG), nodular goiter (NG), diffuse goiter(DG), thyroiditis with or without nodule were $24(18,3 \%), 51(38,9 \%), 27$ ( $20.6 \%), 10$ $(7,6 \%), 19(14.6 \%)$, respectively (Table 2$)$.

Conclusion: There is a complex interaction between thyroid disorders and diabetes mellitus. According to various study, the most common thyroid disorder in diabetics is hypothyroidism $(2,4)$. Although the prevalence of thyroid dysfunction in our patients is concordant with previous results, sc-hyper is more prevalent than sc-hypo. These differences may result from iodine status, geographical location, ethnic characteristics and autoimmune status of the study population. In comparison with non-diabetic controls, higher prevalence of Sc-hyper has been reported in the patients with T2D (4\% versus 2,4\%) (5). According to our results, $81,7 \%$ of diabetics had thyroid gland abnormality by US. In light of these results, all diabetics should be evaluated for thyroid disorders.
Table 1. The characteristics and ultrasound findings of the patients

\begin{tabular}{lccc}
\hline & Female & Male & P value \\
\hline Age (year) & $55 \pm 10,1$ & $59 \pm 8,8$ & $0,015^{*}$ \\
Duration of diabetes (year) & $6,5 \pm 5,6$ & $6,3 \pm 6,5$ & 0,828 \\
Non-smoke/smoke (n) & $72 / 1$ & $48 / 10$ & $0,002^{*}$ \\
BMl (Kg/m²) & $34 \pm 6$ & $30 \pm 5$ & $0,001^{*}$ \\
FPG (mg/dl) & $163 \pm 60$ & $179 \pm 77$ & 0,178 \\
HbA1c (\%) & $7,6 \pm 1,8$ & $7,5 \pm 1,8$ & 0,093 \\
Total Chol (mg/dl) & $201 \pm 47$ & $188 \pm 44$ & 0,125 \\
Triglyceride (mg/dl) & $179 \pm 123$ & $183 \pm 120$ & 0,883 \\
HDL-Chol (mg/dl) & $50 \pm 14$ & $43 \pm 11$ & $0,001^{*}$ \\
Ldl-Chol (mg/dl) & $116 \pm 35$ & $101 \pm 35$ & 0,416 \\
Tsh (mlU/L) & $1,9 \pm 1,3$ & $1,5 \pm 1,2$ & 0,121 \\
Thyroid volume & $20,4 \pm 11,5$ & $30,1 \pm 15,1$ & $0,000^{*}$ \\
$\begin{array}{l}\text { Dominant nodule } \\
\text { Diameter ** }\end{array}$ & $14,2 \pm 9,9$ & $13,6 \pm 10,2$ & 0,770 \\
\hline $\begin{array}{l}\text { * P <0,05 value was accepted as statistically } \\
\text { patients with nodule }\end{array}$ & & \\
\hline & & & \\
\hline
\end{tabular}

Table 2. Thyroid ultrasound findings

\begin{tabular}{lccc}
\hline US Finding & $\begin{array}{c}\text { Female } \\
\mathrm{n}(\%)\end{array}$ & $\begin{array}{c}\text { Male } \\
\mathrm{n}(\%)\end{array}$ & Total \\
\hline Normal & $13(17,8 \%)$ & $11(19 \%)$ & $24(18,3 \%)$ \\
Multinodular goiter & $30(41,1 \%)$ & $21(36,2 \%)$ & $51(38,9 \%)$ \\
Nodular goiter & $16(21,9 \%)$ & $11(19 \%)$ & $27(20,6 \%)$ \\
$\begin{array}{l}\text { Diffuse goiter } \\
\begin{array}{l}\text { Thyroiditis } \\
\text { with/without nodule }\end{array}\end{array}$ & $4(5,5 \%)$ & $6(10,3 \%)$ & $10(7,6 \%)$ \\
\hline
\end{tabular}

\footnotetext{
References

1. Junik R, Kozinski M, Debska-Kozinska K Thyroid ultrasound in diabetic patients without overt thyroid disease. Acra Radiol. 2006;47(7):687-91

2. Uppal V, Vij C, Bedi GK, Vij A, Banerjee BD. Thyroid disorders in patients of type 2 diabetes mellitus. Indian J Clin Biochem. 2013;28(4):336-41

3. Duran AO, Anil C, Gursoy A, et al. Thyroid volume in patients with glucose metabolism disorders. Arq Bras Endocrinol Metabol, 2014;58(8):824-7

4. Palma CC, Pavesi M, Nogueira VG, et al. Prevalence of thyroid dysfunction in patients with diabetes mellitus. Diabetol Metab Syndr. 2013;5(1):58

5. Díez JJ, Iglesias P. Subclinical hyperthyroidism in patients with type 2 diabetes. Endocrine. 2012;42(1):157-63
} 